\title{
O ENSINO FUNDAMENTAL NO BRASIL: BREVES REFLEXÕES SOBRE A TRAJETÓRIA HISTÓRICA, AS RAZÕES IMPLÍCITAS E IMPLICAÇÕES PRÁTICAS PARA O ENSINO DE 9 ANOS
}

\section{THE PRIMARY EDUCATION IN BRAZIL: BRIEF REFLECTIONS ON THE HISTORICAL TRAJECTORY, THE IMPLIED REASONS AND PRACTICAL IMPLICATIONS FOR TEACHING OF NINE YEARS}

\author{
MEDEIROS, Michele Hirsch de \\ michele.hdemedeiros@gmail.com \\ UNICENTRO - Universidade Estadual do Centro Oeste \\ LIRA, Aliandra Cristina Mesomo \\ aliandralira@gmail.com \\ UNICENTRO - Universidade Estadual do Centro- Oeste
}

\begin{abstract}
RESUMO Este artigo tem o objetivo de explicitar questões históricas referentes à organização do ensino fundamental no Brasil, em especial a legislação mais recente que delineou a atual configuração desse nível de ensino em 9 anos, com ênfase para os aspectos relacionados à realidade do estado do Paraná. A partir de um levantamento histórico embasado em leis e documentos que orientaram e orientam o ensino fundamental, o texto problematiza as razões sociais, políticas e econômicas que podem ter influenciado a decisão de ampliação desse nível de ensino, assim como a obrigatoriedade da matrícula no primeiro ano das crianças na faixa etária de 6 anos de idade.
\end{abstract}

Palavras-chave: Ensino Fundamental. História. Legislação.

ABSTRACT This article aims to explain historical issues concerning the organization of basic education in Brazil, especially the latest legislation outlined the current configuration of this educational level in nine years, with emphasis on aspects related to the state of Paraná reality. From a historical survey grounded in laws and documents that guide and direct the elementary school, the text discusses the social reasons, political and economic changes that may have influenced the decision to expand this level of education, as well as the registration requirement in the first year of children aged 6 years old.

Keywords: Elementary Education. History. Legislation.

\section{INTRODUÇÃO}

A ampliação do ensino fundamental de 8 para 9 anos regulamentada pela Lei 11.274 (BRASIL, 2006) em 2006, embora já indicada pela Lei de Diretrizes e Bases da Educação Nacional (LDB) 9394 (BRASIL, 1996) gerou muitas controvérsias e desafios tanto aos sistemas de ensino, quanto para as crianças. Ainda hoje, muitas perguntas estão sem resposta, principalmente com relação às razões reais (e não apenas as proclamadas) para tal ampliação, ao corte etário e, principalmente, às 
práticas a serem desenvolvidas com as crianças nos primeiros anos do ensino fundamental.

Do ponto de vista organizacional, no contexto brasileiro, o ensino fundamental integra a educação básica, juntamente com a educação infantil e o ensino médio. Ou seja, por lei, o ensino fundamental é um nível de ensino responsável pela educação escolar de crianças e adolescentes de seis a quatorze anos, que se desenvolve, predominantemente, em instituições próprias (BRASIL, 1996). Esse nível de ensino faz parte do sistema de ensino brasileiro, sendo que sua estrutura e funcionamento são regulamentados pelos órgãos superiores, dentre eles o Ministério da Educação (MEC), as Secretarias Estaduais e Municipais de Educação, Conselho Nacional de Educação (CNE) e Conselho Estadual de Educação (CEE). Nos municípios devem estar organizados os Conselhos Municipais de Educação, com o intuito de pensar e propor ações mais voltadas para a realidade local.

Pedra angular da Educação Básica, o Ensino Fundamental tem constituído foco central da luta pelo direito à educação. Em consequência, no Brasil, nos últimos anos, sua organização e seu funcionamento têm sido objeto de mudanças que se refletem nas expectativas de melhoria de sua qualidade e de ampliação de sua abrangência, consubstanciadas em novas leis, normas, sistemas de financiamento, sistemas de avaliação e monitoramento, programas de formação e aperfeiçoamento de professores e, o mais importante, em preocupações cada vez mais acentuadas quanto à necessidade de um currículo e de novos projetos político-pedagógicos que sejam capazes de dar conta dos grandes desafios educacionais da contemporaneidade (BRASIL, 2013, p. 103).

Ao longo da história da educação brasileira, quando legalmente orientado pela legislação educacional, o ensino fundamental sofreu diversas modificações estruturais, inclusive em sua nomenclatura. A partir desse momento vamos perfazer, brevemente, os passos históricos os quais envolveram esse nível de ensino, levando em conta questões sociais, políticas e econômicas envolvidas nas alterações ocorridas. Trata-se de estudo bibliográfico com suporte a autores da área de história da educação e políticas educacionais, com análise da legislação que contempla orientações para a organização do ensino fundamental.

A discussão ora apresentada ganha importância uma vez que o conhecimento das questões legais deve vir acompanhado da necessária reflexão crítica acerca dos encaminhamentos tomados e dos desdobramentos das políticas educacionais que envolvem o ensino fundamental. 


\section{A LDB 4024/61, A LDB 5692/71 E A LDB 9394/96: DO ENSINO PRIMÁRIO AO ENSINO DE PRIMEIRO GRAU PARA O ENSINO FUNDAMENTAL}

Do ponto de vista histórico são relativamente recentes as disposições legais que tratam da organização do ensino no Brasil. A primeira Lei de Diretrizes e Bases da Educação Nacional, a Lei 4024 (BRASIL, 1961), estabeleceu diretrizes para o então chamado ensino primário que era composto por no mínimo quatro séries, podendo ser ampliado para até seis séries. Esse nível de ensino, que hoje corresponde ao ensino fundamental, tinha como objetivo, segundo a lei:

Art. 25. O ensino primário tem por fim o desenvolvimento do raciocínio e das atividades de expressão da criança, e a sua integração no meio físico e social (BRASIL, 1961).

O ingresso nessa etapa do ensino era obrigatório a partir dos sete anos de idade completos, como previa o artigo 27 da lei:

Art. 27. O ensino primário é obrigatório a partir dos sete anos e só será ministrado na língua nacional. Para os que o iniciarem depois dessa idade poderão ser formadas classes especiais ou cursos supletivos correspondentes ao seu nível de desenvolvimento (BRASIL, 1961).

Meneses (2002, p. 96) tece algumas considerações sobre a educação básica a partir da LDB 4024, de 1961:

Com a Lei de Diretrizes e Bases (LDB) - Lei o 4024, de 20/12/61- dá-se um importante passo no sentido da unificação do sistema de ensino e da eliminação do dualismo administrativo herdado do Império. Inicia-se pela primeira vez, uma relativa descentralização do sistema como um todo, concedendo-Ihe considerável margem de autonomia aos estados e proporcionando-Ihes as linhas gerais a serem seguidas na organização de seus sistemas, linhas estas que deveriam responder por uma certa unidade entre eles.

E ainda, propriamente sobre a organização do ensino primário, comenta:

Mantendo a tradicional autonomia dos estados quanto à organização do ensino primário, a LDB limitou-se a um mínimo de dispositivos referentes a esse nível de instrução, não indo muito além da fixação de suas finalidades, duração e obrigatoriedade (MENESES, 2002, p. 97).

Segundo o autor, a LDB 4024 (BRASIL, 1961), não conseguiu resolver a questão da descontinuidade entre 0 ensino primário e o ensino médio, o que 
continuava se configurando como um problema na extensão e continuidade do processo de escolarização da época.

Já na LDB 5692 (BRASIL, 1971), de 11 de agosto de 1971, o até então chamado ensino primário passou a ser denominado ensino de primeiro grau, e objetivava a formação da criança e/ou adolescente, preparo para o trabalho e para o exercício da cidadania, como dispõe em seu artigo primeiro:

Art. $1^{\circ} \mathrm{O}$ ensino de $1^{\circ}$ e $2^{\circ}$ graus tem por objetivo geral proporcionar ao educando a formação necessária ao desenvolvimento de suas potencialidades como elemento de auto realização, qualificação para o trabalho e preparo para o exercício consciente da cidadania (BRASIL, 1971).

Observe-se que com relação aos objetivos apresentados na legislação anterior, acrescentou-se a ênfase na formação para o mercado de trabalho. 0 ensino de primeiro grau tinha a duração de oito anos e a lei estabelecia como obrigatória a matrícula das crianças com sete anos de idade nesse nível de ensino.

Art. 17. $O$ ensino de $1^{\circ}$ grau destina-se à formação da criança e do préadolescente, variando em conteúdo e métodos segundo as fases de desenvolvimento dos alunos.

Art. 18. O ensino de $1^{\circ}$ grau terá a duração de oito anos letivos e compreenderá, anualmente, pelo menos 720 horas de atividades.

Art. 19. Para o ingresso no ensino de $1^{\circ}$ grau, deverá o aluno ter a idade mínima de sete anos (BRASIL, 1971).

Segundo Azanha (1993, apud MENESES, 2002, p. 116):

Com a promulgação de uma nova Lei de Diretrizes e Bases em 1971, houve alterações radicais na política educacional. As mais profundas foram a fusão dos antigos primário e ginasial num curso único de oito anos e reorganização de todo 0 ensino de $2^{\circ}$ grau (antigo ginasial) para dar-lhe feição terminal profissionalizante.

Assim, buscava-se superar o problema da descontinuidade entre o nível primário e médio que até a LDB 4024 (BRASIL, 1961) não havia sido enfrentado. A lei 5692 (BRASIL, 1971) vigorou por um longo tempo, vinte e cinco anos, até que depois de muitas discussões, reivindicações e luta dos profissionais da área da educação para uma mudança no sistema educacional brasileiro, o Congresso Nacional sancionou a LDB 9394 (BRASIL, 1996), em 20 de dezembro de 1996, lei 
que dispõe sobre as diretrizes e bases do nosso sistema educacional até hoje, com algumas alterações.

A LDB 9394 (BRASIL, 1996), seguindo determinações da Constituição de 1988 em seu artigo 205, prevê a educação como direito de todo cidadão, visando o desenvolvimento e preparo para a cidadania, incluindo sua qualificação para o mundo do trabalho. Como dever do Estado e da família, com relação à obrigatoriedade, tanto a Constituição quanto a LDB estabelecem os mesmos princípios. A Constituição Federal (BRASIL, 1988) em seu artigo 208 estabelece e garante o Ensino Fundamental, obrigatório e gratuito, inclusive para os que não tiveram acesso na idade própria, como dever do Estado. A LDB 9394 (BRASIL, 1996) dispõe, em seu artigo 4ํㅜ, Título III, Do Direito à Educação e do Dever de Educar:

Art. 4ํ. O dever do Estado com a educação escolar pública será efetivado mediante a garantia de:

I - ensino fundamental, obrigatório e gratuito, inclusive para os que a ele não tiveram acesso na idade própria; [...] (BRASIL, 1996).

A partir de então, o ensino fundamental passou a ter a duração mínima de 8 anos e ampliou os seus objetivos, sendo que a obrigatoriedade para a matrícula de ingresso ao ensino fundamental com 8 anos de duração era aos sete anos de idade:

Art. 32. . ensino fundamental, com duração mínima de oito anos, obrigatório e gratuito na escola pública, terá por objetivo a formação básica do cidadão, mediante:

I - o desenvolvimento da capacidade de aprender, tendo como meios básicos o pleno domínio da leitura, da escrita e do cálculo;

II - a compreensão do ambiente natural e social, do sistema político, da tecnologia, das artes e dos valores em que se fundamenta a sociedade;

III - o desenvolvimento da capacidade de aprendizagem, tendo em vista a aquisição de conhecimentos e habilidades e a formação de atitudes e valores; IV - o fortalecimento dos vínculos de família, dos laços de solidariedade humana e de tolerância recíproca em que se assenta a vida social (BRASIL, 1996).

Saviani (1997, p. 210) refere-se à LDB 9394 (BRASIL, 1996) como "[...] uma importante conquista no sentido de se caminhar em direção a um verdadeiro sistema nacional de educação abrangente e universalizado, isto é, capaz de garantir a plena escolaridade a toda à população do país", mas salienta:

É preciso, no entanto, não perder de vista que o conceito de educação básica adotado implica não apenas uma reordenação do ensino fundamental, mas o empenho decidido em universalizar o ensino médio na perspectiva de uma 
escola unificada, capaz de articular a diversidade de experiências e situações em torno do objetivo de formar seres humanos plenamente desenvolvidos e, pois, em condição de assumir a direção da sociedade ou de controlar quem dirige.

\section{A AMPLIAÇÃO DO ENSINO FUNDAMENTAL: COMO PASSAMOS DE 8 PARA 9 ANOS}

Dando continuidade à perspectiva de universalização da educação básica, em 2001, o Plano Nacional da Educação, Lei 10.172 (BRASIL, 2001), estabeleceu como uma de suas metas para a década 2001- 2010 "Ampliar para nove anos a duração do ensino fundamental obrigatório com início aos seis anos de idade, à medida que for sendo universalizado o atendimento na faixa etária de 7 a 14 anos", (BRASIL, 2001) com o objetivo de oferecer maiores oportunidades de aprendizagem às crianças e um maior nível de escolaridade. Tanto a Constituição de 1988, como a LDB 9394 (BRASIL, 1996) e o Plano Nacional de Educação apresentam como um de seus objetivos proclamados a garantia do padrão de qualidade de ensino. Assim, no plano legal, a ampliação do ensino fundamental de 8 para 9 anos surge como uma possibilidade de melhoria da educação.

Em 2004, o Conselho Nacional de Educação, juntamente com a Câmara de Educação Básica, iniciou uma série de encontros regionais sobre a ampliação do Ensino Fundamental até então com 8 anos de duração, para 9 anos. Nesses encontros, alguns estados que já haviam implantado o ensino fundamental de 9 anos em seus sistemas de ensino, apresentaram ponderações sobre suas experiências exitosas com a ampliação, sendo também promovidas discussões entre representantes das secretarias estaduais e municipais sobre a ampliação. Além disso, os estados e municípios participantes recebiam um documento com as primeiras orientações e objetivos da ampliação, o qual era analisado coletivamente em grande assembleia (Parecer CNE/CEB ํo6/2005). Esses encontros foram o início de uma série de pareceres, orientações e documentos para a efetiva ampliação do ensino fundamental na maioria dos estados brasileiros no ano de 2006.

A Lei $n=11.114$ (BRASIL, 2005), do dia 16 de maio de 2005, estabeleceu a obrigatoriedade da matrícula das crianças de seis anos de idade no ensino fundamental, alterando a LDB 9394 (BRASIL, 1996) em seus artigos 6, 30, 32 e 87, que passaram a vigorar com a seguinte redação: 
Art. $6^{\circ}$. É dever dos pais ou responsáveis efetuar a matrícula dos menores, a partir dos seis anos de idade, no ensino fundamental.

Art. 30.[....]

II - (VETADO)

Art. $32^{\circ}$. O ensino fundamental, com duração mínima de oito anos, obrigatório e gratuito na escola pública a partir dos seis anos [...].

\section{Art.87.[...]}

$3^{0}[\ldots]$

I - matricular todos os educandos a partir dos seis anos de idade, no ensino fundamental, atendidas as seguintes condições no âmbito de cada sistema de ensino:

a) plena observância das condições de oferta fixadas por esta Lei, no caso de todas as redes escolares;

b) atingimento de taxa líquida de escolarização de pelo menos $95 \%$ (noventa e cinco por cento) da faixa etária de sete a catorze anos, no caso das redes escolares públicas; e

c) não redução média de recursos por aluno do ensino fundamental na respectiva rede pública, resultante da incorporação dos alunos de seis anos de idade; [...] (BRASIL, 2005).

Apesar das mudanças no artigo 32, talvez pela rapidez com que tramitou no congresso, a lei 11.114 (BRASIL, 2005) deixou uma lacuna que causou grandes conflitos na área educacional. Ao mesmo tempo em que indicava a entrada obrigatória das crianças aos seis anos de idade no ensino fundamental, foi mantida a parte do artigo 32 da LDB que definia a duração de 8 anos para o ensino fundamental obrigatório e gratuito na escola pública. Ou seja, antecipava-se a entrada da criança, sem com isso assegurar a ela mais um ano de escolarização obrigatória. Devido a este impasse, logo em seguida o Conselho Nacional de Educação, em junho de 2005, homologou o Parecer 6/2005, que reexaminou o Parecer 24/2004, acrescentando a ampliação do ensino fundamental obrigatório para 9 anos, a partir dos seis anos de idade (BAPTISTA; LIMA, 2013).

Somente com a redação do Parecer 6/2005 é que se esclarece a obrigatoriedade da matrícula aos seis anos de idade e a duração de 9 anos do ensino fundamental. Além disso, o Parecer ainda estabelece as condições para que isso se efetive de forma a garantir uma educação de qualidade para a nova faixa etária contemplada.

Já no início de 2006, a Lei 11.274 (BRASIL, 2006a), de 6 de fevereiro, fixa em seu art. $5^{\circ}$, o prazo final para a implementação do ensino fundamental de 9 anos, aos Municípios, Estados e o Distrito Federal, que teriam até 2010 para efetivar tal orientação. 
A lei da obrigatoriedade de ingresso aos 6 anos (Lei Federal ํ⒒114) foi aprovada sem que houvesse uma adequação do sistema de ensino, e todos (secretarias estaduais e municipais assim como escolas públicas e privadas) foram induzidos a receber as crianças que estavam fora da escola sem ter conseguido preparar os professores, os pais e as próprias crianças (BARBOSA et al, 2012, p. 25).

Salvo algumas exceções, a implantação, nos estados e municípios, não foi acompanhada pela devida preparação dos professores, estrutura física institucional e reorganização das propostas pedagógicas, sendo essas questões atropeladas e não estudadas e planejadas mais a fundo. Em especial, uma série de dúvidas e questionamentos foram surgindo em relação a como proceder pedagogicamente diante dessa nova organização, e principalmente, com o primeiro ano que receberia crianças de seis anos de idade.

Segundo as orientações pedagógicas repassadas pelo Conselho Nacional de Educação/ Câmara da Educação Básica (CNE/CEB), o primeiro ano do ensino fundamental de 9 anos não teria o formato da educação infantil e nem da antiga primeira série do ensino fundamental de 8 anos. Por parte do CNE e do Ministério da Educação (MEC) foram elaborados, então, alguns documentos para auxiliar as secretarias estaduais e municipais a reestruturarem suas propostas para esse nível, sendo os principais: Ensino Fundamental de Nove Anos - Orientações Gerais (BRASIL, 2004), Ensino Fundamental de Nove Anos - Orientações para a Inclusão da Criança de Seis Anos de Idade (BRASIL, 2006b), Diretrizes Curriculares Nacionais para o Ensino Fundamental de Nove Anos (BRASIL, 2013).

As Diretrizes Curriculares Nacionais para o Ensino Fundamental de Nove Anos ressaltam que o ensino fundamental é um direito de todo cidadão com vistas a sua formação (BRASIL, 2013), sendo interpretado, portanto, como um nível de ensino essencial, indispensável, imprescindível.

Assim, o entendimento deveria ser que

[...] as crianças são atores sociais que, através das interações sociais, produzem culturas. As crianças assimilam, mas também interferem no mundo em que vivem. Para uma criança, tornar-se humana é preciso tempo, é preciso estar junto, é preciso brincar, e muitas outras coisas que nosso modelo de escola de ensino fundamental nega, na medida em que apenas investe nos conteúdos de ensino. Atuamos em nossas escolas com alunos, não com crianças (BARBOSA et al, 2012, p. 33). 
O ponto chave do ensino fundamental de 9 anos é a reorganização da proposta pedagógica, respeitando a criança em suas fases específicas de desenvolvimento, ou seja, respeitando o direito de ser criança antes de ser aluno.

A justificativa apresentada pelo governo para a ampliação do ensino fundamental e para a obrigatoriedade da matrícula das crianças de seis anos de idade no primeiro ano é a de oportunizar melhores e maiores condições de aprendizagem, aumentando o índice de permanência na escola. Diante dos argumentos elencados nos documentos oficiais, é inquietante considerar que a ampliação do ensino fundamental seja mais uma formalidade política do que uma verdadeira alternativa para os graves e antigos problemas da educação básica brasileira (CRAIDY; BARBOSA, 2012).

Como assinalam Cury e Ferreira (2010), a obrigatoriedade da educação básica dos quatro aos dezessete anos de idade subentende legalmente que toda criança e adolescente nesta faixa etária deveria estar frequentando a escola. Porém, o que se constata, em relação ao ensino fundamental, é que o Brasil está praticamente universalizando a matrícula das crianças e dos adolescentes, o que não significa na realidade que esta etapa da educação esteja realmente sendo universalizada, pois uma situação é a criança ou adolescente estar matriculado no ensino fundamental e outra é efetivamente estar cursando o ensino fundamental e aprendendo. Assim, segundo os autores, "[...] universalizamos a matrícula, mas não o ensino" (p. 140), ou seja, não é suficiente estar na escola, é também necessário que as crianças e adolescentes aprendam, avancem em suas aprendizagens.

A falta de compromisso em relação à aprendizagem fica evidente diante dos resultados dos indicadores de desempenho escolar como o Índice de Desenvolvimento da Educação Básica (IDEB) e o Sistema de Avaliação da Educação Básica (SAEB), pois problemas como a repetência, a evasão, a exclusão e a defasagem idade/série continuam "[...] atestando a incapacidade do sistema educacional em escolarizar a todos, como direito fundamental definido na Constituição" (CRAIDY; BARBOSA, 2012, p. 20).

Contudo, como já o fizeram outros autores, é oportuno avaliar se realmente o objetivo proclamado é o objetivo real, pois o Brasil precisava elevar o nível de escolaridade da população e, desta forma diminuir o analfabetismo no país. Em nível internacional, o país precisava melhorar esses índices e a ampliação do ensino 
fundamental poderia estar servindo também a esse propósito. Embora nem todos declarados, pode-se deduzir que foram muitos os interesses que levaram o Conselho Nacional de Educação e a Câmara de Educação Básica a propor e efetivar a ampliação do ensino fundamental de 9 anos em território nacional.

[...] No início do século XXI, o Brasil vinha sendo pressionado a ampliar a obrigatoriedade de anos escolares, pois é um dos países da América Latina com menor tempo de obrigatoriedade para as crianças (BARBOSA et al, 2012, p. 21).

Craidy e Barbosa (2012) ainda lembram que uma orientação como essa, assentada na justificativa de melhoria do ensino, precisa ser considerada em seu contexto. Ou seja, ano pré-eleitoral, em que as medidas rápidas pretenderam atender às questões estatísticas internacionais, da diminuição do analfabetismo, da repetência e defasagem entre idade cronológica e ano escolar, sendo um ótimo marketing de campanha eleitoral, mas uma proposta pouco debatida ou discutida nos âmbitos competentes para tal.

As razões financeiras também precisam ser consideradas, uma vez que as crianças de seis anos de idade, antes da ampliação, faziam parte da população sem fundos financeiros específicos para custear a sua educação, a educação infantil, pois o Fundo de Manutenção e Desenvolvimento do Ensino Fundamental (FUNDEFanterior ao Fundo de Manutenção e Desenvolvimento da Educação Básica e Valorização do Magistério- FUNDEB) era um fundo específico para os alunos até então matriculados no ensino fundamental. Sendo assim, a ampliação otimizaria os recursos financeiros de mais uma parte da população, já que o investimento na matrícula no ensino fundamental das crianças de seis anos resultaria em mais dinheiro para os municípios, pois os valores destinados estavam relacionados ao número de alunos atendidos.

Arelaro (2005, p. 1047) comenta sobre essa política e seus desdobramentos:

[...] é de se supor que o autor dessa lei só tenha pretendido ampliar a possibilidade de uso dos recursos do FUNDEF com crianças menores, uma vez que os municípios se encontram em dificuldades para ampliar sua rede de educação infantil, sem contar com o aporte dos recursos do FUNDEF. Alguns especialistas também garantem que a proposta constante do PNE responde, também, a essa necessidade de ampliação dos recursos municipais, e, portanto, 0 atendimento às crianças matriculadas na educação infantil passaria a ser realizado "disfarçado" de ensino fundamental. Mas manter-se-iam, nesse $1^{\circ}$ ano de ensino fundamental "antecipado", as premissas e as orientações da educação infantil. 
Só mais tarde essa questão foi regulamentada com a aprovação do FUNDEB, responsável pelos fundos financeiros de todos os níveis da educação básica em substituição ao FUNDEF, que vigorou de 1998 a 2006. O FUNDEB foi aprovado em 2007, pela Lei oㅜ 11.494 (BRASIL, 2007).

\section{O CORTE ETÁRIO PARA A MATRÍCULA DAS CRIANÇAS NO PRIMEIRO ANO DO ENSINO FUNDAMENTAL: DIVERSIDADE E CONTROVÉRSIAS}

Uma das maiores dúvidas, que gerou um dos problemas enfrentados pelos estados na efetivação da ampliação do ensino fundamental de 9 anos, foi com relação à definição da data de corte para a matrícula das crianças, já que a lei prevê "[...] matricular todos os educandos a partir dos 6 (seis) anos de idade no ensino fundamental" (BRASIL, 2005).

Os Pareceres CNE/CEB n. 6/2005, n.ำ 18/2005, n. 5/2007 e n. 4/2008 regulamentam a data corte para o ingresso no ensino fundamental como o início do ano letivo: "Compreenda-se "início do ano letivo" como o primeiro dia de aula do ano, previsto no calendário escolar do respectivo sistema de ensino" (CNE/CEB no 22/2009). Segundo Baptista e Lima (2013), o relator do Parecer 5/2007, ao mencionar a dificuldade de compreensão dessa regulamentação, questiona sobre as possíveis indefinições referentes à data de corte, insistindo que o texto é claro e não pode alimentar dúvidas sobre o que significa seis anos completos ou a completar até o início do ano letivo.

Todos os documentos oficiais expedidos pelo Conselho Nacional de Educação afirmam e reafirmam que a entrada da criança no ensino fundamental de 9 anos deverá ser feita aos seis anos de idade. Contudo, a flexibilidade, por parte desse mesmo Conselho, permitindo que nos anos de 2010 e 2011 os sistemas de ensino matriculassem as crianças com cinco anos de idade no primeiro ano do ensino fundamental para evitar rupturas no processo educacional das crianças que porventura já estavam inseridas no nível fundamental, permitiu exceções que levaram às ações civis públicas, com vistas a tornar legal a matrícula das crianças no primeiro ano aos cinco anos de idade, independentemente da condição acima mencionada. 
Desse modo, diante de diversas ações judiciais, a data de corte para as matrículas é diferenciada no território nacional. Segundo a Professora Sônia Maria Aranha $^{1}$, as datas de corte atualmente estão assim regulamentadas:

\begin{abstract}
Para os estados de Rondônia, Amazonas, Roraima, Acre, Amapá, Pará, Maranhão, Piauí, Ceará, Rio Grande do Norte, Paraíba, Alagoas, Sergipe, Espírito Santo, Mato Grosso do Sul, Santa Catarina, Rio Grande do Sul. Municípios do interior paulista e São Paulo, capital, a data é 31 de março. Em Mato Grosso segundo a Resolução CEE-MT n.002/2009, 30 de abril. Em São Paulo, nas escolas públicas estaduais (exceto as localizadas na capital paulista) e escolas particulares e em Minas Gerais, 30 de junho. No estado do Rio de Janeiro e no Paraná, 31 de dezembro. Os Estados de Pernambuco e Bahia possuem sentença judicial conquistada pelo Ministério Público Federal que flexibiliza a data de corte de 31 de março, isto é, se a criança tiver um laudo psicopedagógico que ateste a sua capacidade cognitiva para seguir adiante nos estudos, independente de sua data de nascimento ela poderá ser matriculada no ano pretendido (ARANHA, 2013, s.p.).
\end{abstract}

Todos esses estados, inclusive o Paraná, possuem liminares regularizando a situação em relação à data de corte, contudo as questões jurídicas, de modo geral, pouco se atêm às questões pedagógicas. Cabe considerar que as situações decorrentes dessa flexibilidade da lei acabaram levando estados e municípios a manterem, em suas turmas de primeiro ano, crianças que completam seis anos apenas no final do período letivo, portanto com cinco anos.

De acordo com a LDB 9394 (BRASIL, 1996) as crianças com cinco anos de idade devem frequentar a educação infantil, sendo essa a posição dos documentos oficiais do CNE, dos pesquisadores e fóruns de defesa da educação infantil. $\mathrm{O}$ Parecer $5 / 2007$, não deixa dúvidas sobre o local específico para a frequência das crianças com cinco anos de idade: "A pré-escola é o espaço apropriado para a criança com quatro e cinco anos de idade e também para aquelas que completarão seis anos posteriormente à idade cronológica fixada para matrícula no ensino fundamental" (BRASIL, 2007).

\title{
5 O QUE MUDA NAS ORIENTAÇÕES DO ESTADO DO PARANÁ EM RELAÇÃO ÀS ORIENTAÇÕES FEDERAIS
}

\footnotetext{
${ }^{1}$ Mestre em educação e pedagoga formada pela Unicamp. Diretora de Estudos e Pesquisas do Centro de Estudos Prospectivos de Educação e Cultura. http://www.soniaranha.com.br/
} 
Diante desse quadro diferenciado regionalmente em relação à data corte, cabe compreender como o Estado do Paraná regulamentou e implantou o ensino fundamental de 9 anos, incluindo a data corte vigente.

A primeira Deliberação do Estado do Paraná regularizando e estabelecendo normas para a implantação do ensino fundamental de 9 anos no Sistema Estadual de Ensino do Estado, a Deliberação 03/06 (PARANÁ, 2006), aprovada em 09 de junho de 2006, dispõe em seu Art.10:

\begin{abstract}
Art. 10 - A implantação do ensino fundamental de nove anos deve considerar o regime de colaboração e deverá ser regulamentada pelos sistemas de ensino, que deverão empenhar-se no aprofundamento de estudos e debates, com o objetivo de se implementar o ensino fundamental de nove anos a partir dos seis anos de idade, garantindo a unidade nacional.
\end{abstract}

No final do referido artigo há referência à garantia de uma unidade nacional, mas quanto à idade para o ingresso ao ensino fundamental, mesmo hoje, oito anos depois dos primeiros estados efetivarem a implantação, não existe unanimidade, uma vez que cada sistema estadual de ensino regulamentou a data corte das crianças conforme suas necessidades e também em função da pressão de vários segmentos sociais.

As primeiras orientações do Conselho Estadual de Educação e da Secretaria Estadual da Educação apontaram claramente a data corte, no Art.12 da Deliberação 03/06 (PARANÁ, 2006):

Art. 12 - Para matrícula de ingresso no 1.ำ ano do ensino fundamental de 9 anos de duração o educando deverá ter seis anos completos ou a completar até $1^{\circ}$ de março do ano letivo em curso.

$\S 1 .^{\circ}-$ O aluno que estiver cursando a educação infantil e completar seis anos de idade no decorrer do ano letivo não poderá ingressar no ensino fundamental nesse mesmo ano.

Porém, apesar do estabelecido na referida Deliberação, um grupo de escolas particulares entrou com uma Ação Civil Pública, requerendo que o Conselho Estadual de Educação do Paraná deixasse de fixar critérios cronológicos de acesso ao ensino fundamental no início do ano letivo, no âmbito do Sistema Estadual de Ensino (PARANÁ-CEE, 2008).

Neste sentindo Barbosa et al (2012, p. 34) avaliam: 
A competitividade presente em nossa sociedade, e tão arraigada como ideologia dominante, tem feito com que famílias das camadas médias e altas pressionem as escolas privadas para 0 ingresso cada vez mais precoce das crianças no ensino fundamental. A tal ponto que crianças de 5 anos estavam sendo matriculadas na $1^{\text {a }}$ série, 0 que motivou 0 estabelecimento do parecer do CNE sobre a idade mínima de ingresso: 6 anos completos no primeiro dia do ano letivo. Mesmo assim, o Ministério Público, órgão de proteção das crianças e dos adolescentes, em nome do "direito adquirido", tem autorizado a matrícula no $1^{0}$ ano do ensino fundamental de crianças que irão completar 6 anos.

Frente a essas indefinições, o Conselho Estadual de Educação divulgou a alteração do Art.12 da Deliberação 03/06, que seguia o estabelecido pela lei federal quanto às orientações para a matrícula no primeiro ano do ensino fundamental de 9 anos. O Art.12, por meio da deliberação 02/07 (PARANÁ, 2007), modifica-se para a seguinte redação:

Art. 12 Para matrícula de ingresso no $1^{\circ}$ ano do Ensino Fundamental de 9 anos de duração, o educando deverá ter 6 (seis) anos completos ou a completar no início do ano letivo.

Parágrafo único - Atendida a matrícula dos alunos com 6 (seis) anos completos ou a completar no início do ano letivo, admite-se, em caráter excepcional, o acesso ao ensino fundamental de crianças que completem seis anos no decorrer do ano letivo, desde que atendidos os seguintes requisitos:

a) termo de responsabilidade pela antecipação da matrícula da criança, assinado pelos pais ou responsáveis;

b) explicitação no Regimento Escolar;

c) proposta pedagógica adequada ao desenvolvimento dos alunos;

d) comprovação da existência de vagas no estabelecimento de ensino.

Mesmo sabendo que possuía amparo legal suficiente para fazer valer a entrada das crianças apenas com seis anos completos ou seis anos a completar no início do ano letivo como prevê a LDB 9394 (BRASIL, 1996), o Estado do Paraná cedeu à pressão imposta pelas escolas, como fica claro no depoimento emitido, pelo Presidente do CEE (PARANÁ, 2008), Romeu Gomes de Miranda, em nota de esclarecimento de 12 de novembro de 2008:

Como não interessa a este Conselho estabelecer uma guerra de interpretações, gerando confusão no Sistema, mesmo convencido de que a Lei maior, a LDB e outros dispositivos legais nos dão amplo amparo, orientamos a todos os gestores de Instituições públicas e privadas que sigam as definições do Ministério Público do Paraná, permitindo a matrícula de crianças que completarem seis anos de idade ao longo do ano letivo de 2009, até que haja o julgamento definitivo da Ação Civil Pública n.․4 402/07, ocasião em que o CEE/PR voltará a pronunciar-se sobre a matéria. 
Nesse contexto, foram realizadas as matrículas das crianças no primeiro ano mesmo com seis anos incompletos, até o julgamento definitivo da Ação. Isso aconteceu no ano de 2009, que deu origem à Lei 16.049 (PARANÁ, 2009) de 19 de fevereiro deste mesmo ano, que dispõe sobre o direito à matrícula no primeiro ano do ensino fundamental de 9 anos no estado do Paraná, à criança que completar seis anos até o dia 31 de dezembro do ano em curso.

Cabe considerar que a idade não pode ser considerada um parâmetro adequado para definir o nível de competência de um sujeito, porém entendemos que algo haverá que decidir sobre em qual ano as crianças deverão ser matriculadas. A decisão pela idade de seis anos para a matrícula obrigatória no primeiro ano tem uma longa história, que precisa levar em conta a passagem dos seis para os sete anos como momento diferenciado no desenvolvimento infantil. Embora os principais autores das teorias de desenvolvimento e aprendizagem do século $X X-$ Wallon, Piaget e Vygotsky, vejam diferenças nessa faixa etária, todos afirmam que as transformações estão ligadas não só à idade biológica, mas também às experiências individuais de cada criança (BARBOSA et al, 2012).

Talvez por esse motivo, o Conselho Nacional de Educação e a Secretaria de Educação Básica, nas orientações gerais para a ampliação do ensino fundamental, tenham demonstrado preocupação com as crianças que a partir daquele momento estariam sendo inseridas no ensino fundamental, destacando suas necessidades e especificidades diante das faixas etárias já contempladas anteriormente por esse nível de ensino.

Com base em pesquisas e experiências práticas, construiu-se uma representação envolvendo algumas das características das crianças de seis anos que as distinguem das de outras faixas etárias, sobretudo pela imaginação, a curiosidade, o movimento e o desejo de aprender aliados à sua forma privilegiada de conhecer o mundo por meio do brincar. Nessa faixa etária a criança já apresenta grandes possibilidades de simbolizar e compreender o mundo, estruturando seu pensamento e fazendo uso de múltiplas linguagens (BRASIL/ MEC, 2004, p.19).

Nesse entendimento, ressaltam que as crianças de seis anos de idade apresentam gosto e curiosidade em aprender, sendo que a maioria delas se encontra em uma fase de aguçado interesse em saber mais, principalmente fazendo uso das múltiplas linguagens: "[...] gestual, corporal, plástica, oral, escrita, musical e, 
sobretudo, aquela que the é mais peculiar e específica, a linguagem do faz-de-conta, ou seja, do brincar" (BRASIL/MEC, 2004, p. 20).

Como ressaltam Barbosa et al (2012, p. 24), diante dos objetivos declarados há

[...] a ilusão de que obrigar todas as crianças a ingressarem aos 6 anos na 1르 série seria uma forma de construir uma situação igualitária e democratizar o ensino. Porém, as crianças com maior vulnerabilidade pessoal e social seriam as maiores vítimas de uma entrada compulsória à escola que lhes é totalmente estranha. Não apenas a escola é estranha, por não terem frequentado a educação infantil, como também a cultura escolar não Ihes é familiar, por viverem em um ambiente pouco letrado. Isto é, democratizam-se oportunidades tratando os desiguais como iguais.

Neste sentido, os questionamentos mais frequentes dirigem-se aos encaminhamentos pedagógicos quanto ao trabalho com as crianças no primeiro ano do ensino fundamental de 9 anos, sendo que parte delas frequentou a educação infantil e outra não, e a maioria delas inicia o ano letivo com cinco anos e completa seis no decorrer ou ao final do ano letivo.

O Conselho Nacional de Educação e a Câmara de Educação Básica, no parecer 022/98 (BRASIL, 1998), já orientavam para que os sistemas de ensino na reformulação de suas propostas pedagógicas utilizassem os elementos importantes da educação infantil presentes nas Diretrizes Curriculares Nacionais para a Educação Infantil (BRASIL, 2010), considerando as especificidades da criança como um todo no primeiro ano. O que é proposto pelos documentos oficiais é que a proposta pedagógica para o primeiro ano leve em consideração a integração das orientações para a educação infantil e que não se reduza a uma prática de alfabetização aos moldes da antiga primeira série.

\section{CONSIDERAÇÕES FINAIS}

Ao apresentar e analisar a trajetória do ensino fundamental na educação brasileira, fica evidente a importância de se considerar as repercussões, a longo prazo, da ampliação do ensino fundamental e o ingresso das crianças de seis anos de idade no primeiro ano. Assim, ganham relevância os estudos que se dedicam a acompanhar os desdobramentos e implicações do ponto de vista político e pedagógico da ampliação dos anos de escolarização obrigatória. 
A análise da legislação referente ao ensino fundamental, em especial no que tange à sua ampliação de 8 para 9 anos, permite reconhecer que os documentos tratam de questões gerais relacionadas à organização desse nível de ensino sem adentrar nas especificidades das questões pedagógicas. Se por um lado isso poderia garantir a pluralidade de experiências no contexto brasileiro bastante diverso, por outro lado permite variadas interpretações que acabam por configurar situações em que os direitos das crianças podem ser desrespeitados.

Como foi possível acompanhar, nos diversos estados houve indefinições com a data de corte, aspecto ainda não atendido de acordo com as orientações federais, permanecendo diferenciações. No Estado do Paraná, após determinação judicial no primeiro semestre de 2015 para que a data de corte para ingresso no ensino fundamental fosse 31 de março, como orienta o Conselho Federal de Educação, o Conselho Estadual de Educação, em parceria com o judiciário, considerou um período de transição levando em conta as crianças que já estão matriculadas em turmas de pré-escola, devendo as instituições atenderem essa determinação nas matrículas a serem efetuadas a partir de 2018.

Do ponto de vista das práticas é necessário considerar que o sistema educacional brasileiro é marcado pela exclusão, seletividade, iniquidade, ineficácia, ineficiência e baixa efetividade, e o ensino fundamental obrigatório está longe de ter a qualidade que os documentos apontam, mesmo anos depois da ampliação desse nível de ensino. Sem o devido enfrentamento desses problemas, a estratégia de ampliação e da obrigatoriedade acabará por reproduzir características históricas presentes durante a expansão desse nível de ensino no país, características como improvisação, insuficiência, seletividade, discriminação, qualidade insatisfatória e formalização (FREITAS, 2008).

\section{MICHELE HIRSCH DE MEDEIROS}

Graduada pela Universidade Estadual do Centro-Oeste em Pedagogia, Especialista em Psicopedagogia Institucional pela mesma instituição, Mestre em Educação pelo PPGE - UNICENTRO.

\section{ALIANDRA CRISTINA MESOMO LIRA}


Professora Doutora Permanente do DEPED - UNICENTRO, Professora do PPGE/UNICENTRO e Líder do Grupo de Estudos e Pesquisas em Educação Infantil - GEPEDIN.

\section{REFERÊNCIAS}

ARANHA, S. M. Respondendo suas dúvidas sobre educação. Disponível em <http://www.soniaranha.com.br>. Acesso em: dezembro de 2013.

ARELARO, L. R. G. O ensino fundamental no Brasil: avanços, perplexidades e tendências. Educação e Sociedade, Campinas, v. 26, n. 92, p. 1039-1066, 2005.

BAPTISTA, M. C.; LIMA, R. R. (Orgs.). Dossiê FMEI: 5 anos é na educação infantil. Belo Horizonte, UFMG/Faculdade de Educação, 2013.

BARBOSA, M. C. S.; DELGADO, A. C. C. e Colaboradores. A infância no ensino fundamental de 9 anos. Porto Alegre: Penso, 2012.

BRASIL. Diretrizes Curriculares Nacionais Gerais da Educação Básica. Ministério da Educação. Secretária de Educação Básica. Diretoria de Currículos e Educação Integral. - Brasília: MEC, SEB, DICEI, 2013.

BRASIL. Diretrizes Curriculares Nacionais para a Educação Infantil. Brasília, Ministério da Educação, 2010. Disponível em: <www.mec.gov.br>. Acesso em: 29 de janeiro de 2012.

BRASIL. PARECER CNE/CEB № 22/2009 - APROVADO EM 9 DE DEZEMBRO DE 2009 - Diretrizes Operacionais para a implantação do Ensino Fundamental de 9 (nove) anos. Disponível em: <www.portal.mec.gov.br>. Acesso em: janeiro de 2014.

BRASIL. Parecer CNE/CEB no 4/2008, de 20 de fevereiro de 2008. Orientação sobre os três anos iniciais do Ensino Fundamental de nove anos. Brasília: 2008.

BRASIL. Lei 11.494, de 20 de junho de 2007. Regulamenta o Fundo de Manutenção e Desenvolvimento da Educação Básica e de Valorização dos Profissionais da Educação - FUNDEB, de que trata 0 art. 60 do Ato das Disposições Constitucionais Transitórias. 2007. Disponível em: <www.planalto.gov.br>. Acesso em: 12 de julho de 2013.

BRASIL. PARECER CNE № 5/2007 - CEB - Aprovado em 01.02.2007. Consulta com base nas Leis no 11.114/2005 e n० 11.274/2006, que tratam do Ensino Fundamental de nove anos e da matrícula obrigatória de crianças de seis anos no Ensino Fundamental.. Disponível em: <www.portal.mec.gov.br>. Acesso em: janeiro de 2014.

BRASIL. Lei $n^{0} 11.274 / 2006$, de 06 de fevereiro de 2006. Altera a redação dos arts. 29, 30, 32 e 87 da Lei $n^{\circ}$ 9.394, de 20 de dezembro de 1996, que estabelece as 
diretrizes e bases da educação nacional, dispondo sobre a duração de 9 (nove) anos para o ensino fundamental, com matrícula obrigatória a partir dos 6 (seis) anos de idade. 2006a. Disponível em: <www.mec.gov.br>. Acesso em: dezembro de 2013.

BRASIL. Ensino fundamental de nove anos: orientações para a inclusão da criança de seis anos de idade. MEC/SEB/SEIF. Brasília: FNDE, Estação Gráfica, 2006b.

BRASIL. Parecer CNE/CEB no 18/2005, de 15 de setembro de 2005.

Orientações para a matrícula das crianças de 6 (seis) anos de idade no Ensino Fundamental obrigatório, em atendimento à Lei no 11.114 , de 16 de maio de 2005, que altera os Arts. 6으, 32 e 87 da Lei no 9.394/1996. Brasília: 2005.

BRASIL. PARECER CNE № 6/2005 - CEB - Aprovado em 08.06.2005. Reexame do Parecer CNE/CEB 24/2004, que visa o estabelecimento de normas nacionais para a ampliação do Ensino Fundamental para nove anos de duração. Disponível em: <www.portal.mec.gov.br>. Acesso em: janeiro de 2014.

BRASIL. Lei $n^{\circ} 11.114 / 2005$, de 16 de maio de 2005 - Altera os art. $6^{\circ}, 30$, 32 e 87 da Lei no 9.394/1996, de 20 de dezembro de 1996, com o objetivo de tornar obrigatório o início do ensino fundamental aos seis anos de idade. 2005. Disponível em: <www.mec.gov.br>. Acesso em: dezembro de 2013.

BRASIL. Reexame do Parecer CNE/CEB 24/2004, que visa o estabelecimento de normas nacionais para a ampliação do Ensino Fundamental para nove anos de duração. Brasília: 2005.

BRASIL. Ensino fundamental de nove anos: orientações gerais. Brasília, MEC/SEB/DPE/COEF, 2004.

BRASIL. Lei no 10.172/2001, de 09 de janeiro de 2001. Plano Nacional De Educação - PNE/Ministério da Educação. Brasília, DF: INEP, 2001. Disponível em: <www.mec.gov.br>. Acesso em: dezembro de 2013.

BRASIL. PARECER CNE № 022/1998 - CEB - Aprovado em 17 de dezembro de 1998. Diretrizes Curriculares Nacionais para a Educação Infantil. Disponível em: www.portal.mec.gov.br. Acesso em: março de 2015.

BRASIL. Lei no 9.394/1996, de 20 de dezembro de 1996 - Diretrizes e Bases da Educação Nacional. 1996. Disponível em: <www.mec.gov.br>. Acesso em: dezembro de 2013.

BRASIL. Constituição (1988) - Constituição da República Federativa do Brasil. Brasília: Senado Federal, 1988.

BRASIL. Lei no 5692/1971, de 11 de agosto de 1971 - Diretrizes e Bases da Educação Nacional. 1971. Disponível em:<www.mec.gov.br>. Acesso em: dezembro de 2013. 
BRASIL. Lei no 4024/1961, de 20 de dezembro de 1961 - Diretrizes e Bases da Educação Nacional. 1961. Disponível em: <www.mec.gov.br>. Acesso em: dezembro de 2013.

CRAIDY, C. M.; BARBOSA, M. C. S. Ingresso obrigatório no ensino fundamental aos 6 anos: falsa solução para um falso problema. In: BARBOSA, M. C. S. et al.A infância no ensino fundamental de 9 anos. Porto Alegre: Penso, 2012.

CURY, C. R. J.; FERREIRA, L. A. M. Obrigatoriedade da educação das crianças e adolescentes: uma questão de oferta ou de efetivo atendimento? Nuances: estudos sobre Educação, Presidente Prudente, Ano XVII, v. 17, n. 18, p. 124-145, jan./dez. 2010.

FREITAS, D. N. T. Ação reguladora da União e qualidade do ensino obrigatório. (Brasil, 1998-2007). Educar, Curitiba: Ed. UFPR, n. 31, p. 33-51, 2008.

MENESES, J. G. de C. et al. Estrutura e funcionamento da educação básica. Leituras. 2 ed. São Paulo: Pioneira, 2002.

PARANÁ. Lei no 16.049, de 19 de fevereiro de 2009. Dispõe que terá direito à matrícula no 1‥ Ano do Ensino Fundamental de Nove Anos, a criança que completar 6 anos até o dia 31 de dezembro do ano em curso. 2009.

PARANÁ. CEE. Nota de esclarecimento, de 12 de novembro de 2008. Orientação ao Sistema Estadual de Ensino sobre matrículas no ensino fundamental de nove anos. 2008. Disponível em:

<http://www.educacao.pr.gov.br/modules/noticias/article.php?storyid=701>. Acesso em: 12 de março de 2015.

PARANÁ. Deliberação no 02/2007, de 13 de abril de 2007 - Alteração do artigo 12 da Deliberação n 03/06-CEE. 2007.

PARANÁ. Deliberação no 03/2006, 09 de junho de 2006 - Normas para a implantação do Ensino Fundamental de 9 (nove) anos de duração no Sistema Estadual de Ensino do Estado do Paraná. 2006.

SAVIANI, D. A nova lei da educação: trajetória, limites e perspectivas. São Paulo: Autores Associados, 1997. 